\title{
Public acceptance of coastal zone management efforts: The role of citizen preferences in the allocation of funds
}

\author{
Keith S. Evans*, Caroline L. Noblet, Emma Fox, \\ Kathleen P. Bell, and Abigail Kaminski
}

\begin{abstract}
We investigate allocation of funds by citizens across management options addressing impairments to coastal water quality. We study systematic variation in citizen allocation of funds to adaptive versus preventative strategies including the impact of referundum choices and test whether allocations will be impacted by cuing in the design of the referendum. Two key policy insights from our results: citizens who vote no on a water quality referendum have different preferences over allocating funds and providing cues to voters influenced allocation behavior. These results can assist decision makers in thinking about language used to communicate coastal water quality issues, particularly budget referenda.
\end{abstract}

Key Words: budget allocation, coastal water quality, fractional multinomial logit, referendum-style question, shares-allocation model

JEL-Classification: Q25 Q58 H72

Interfaces between human and natural systems increase in importance as populations rise in coastal regions. Estimates indicate approximately 40 percent of the world's population lives within 75 miles $(100 \mathrm{~km})$ of the coast, with this projected to increase over the next decade (Carter 2002, Fleming et al. 2006, National Oceanic and Atmospheric Administration (NOAA) 2013).

Dr. Keith S. Evans is an Assistant Professor in the School of Economics and School of Marine Sciences at the University of Maine. Dr. Caroline L. Noblet is an Assistant Professor in the School of Economics at the University of Maine. Dr. Kathleen P. Bell is a Professor in the School of Economics at the University of Maine. Emma Fox and Abigail Kaminski are graduate students in the School of Economics at the University of Maine. Correspondence: Keith S. Evans - School of Economics \& School of Marine Sciences - 5782 Winslow Hall - University of Maine " Orono, Maine 04469 -Phone: (207) 581-3178 - Fax (207) 581-4278 - Email keith.evans@maine.edu Caroline L. Noblet - School of Economics - 5782 Winslow Hall University of Maine - Orono, Maine 04469 - Phone: (207) 581-3172 - Fax (207) 581-4278 - Email: caroline.noblet@maine.edu

The views expressed are the authors' and do not necessarily represent the policies or views of any sponsoring agencies.

* The first two authors are in alphabetical order and agree to equal contribution and credit.

Agricultural and Resource Economics Review 46/2 (August 2017) 268-295

(C) The Author(s) 2017. This is an Open Access article, distributed under the terms of the Creative

Commons Attribution licence (http://creativecommons.org/licenses/by/4.0/), which permits unrestricted re-use, distribution, and reproduction in any medium, provided the original work is 
A myriad of sustainability issues challenge management of key coastal resources and pose risks to both human (e.g., pathogenic bacteria and toxic dinoflagellates, Vibrio spp. and Alexandrium spp.) and marine (e.g., pollution and overharvesting) health. Research on interactions between human and natural systems argues that now more than ever, policy and management decisions need to be based on a sound body of scientific evidence (Bennett 2016). Sustainability science integrates information about human behaviors, including perceptions and attitudes, and biophysical data (Clark and Dickson 2003, Kates 2011) to empower science-driven policy decisions. Data on citizen perceptions are particularly valuable as public acceptance of a policy is a key to successful implementation and citizens may lack the opportunity for direct input into policy decisions. It is important to note both the costs and benefits associated with citizen engagement in natural resource decision making. Public participation can improve the legitimacy and quality of decision making by helping to identify problems to be addressed and assess the potential acceptance of proposed solutions (Dietz and Stern 2008). However, many citizens may lack knowledge about the link between the provision of government services and the payment for those services (Robbins, Simonsen, and Feldman 2008, Guo and Neshkova 2013). The same may be said for resource management programs, such as coastal water quality monitoring and protection. From a citizen's perspective, the cost of gathering information to become knowledgeable about government services or resource issues may substantially outweigh the benefits of that knowledge (Robbins, Simonsen, and Feldman 2008). Recognizing that citizen participation in policy decisions is complex, potentially rife with conflict, and/or expensive, direct citizen involvement may also provide substantial benefits. These benefits may include legitimizing the decision-making process and creating more effective policy measures (Robbins, Simonsen, and Feldman 2008). Guo and Neshkova (2013 p. 331) call public involvement, "a way to inject democracy into decisions." Direct citizen involvement also provides the kind of evidence that Bennett (2016) argues is necessary for addressing coupled human and natural systems problems, such as coastal water quality management. There is a growing need for structured public preference information in the policy arena, especially for decisions about environmental quality (McDaniels 1996).

Given the variety of challenges facing coastal waters, and the differences in citizen understanding of these threats, future coastal policies will include multiple interventions that are highly dependent on public acceptance. We set our study in Maine and New Hampshire in the United States, where coastal waters drive important components of the states' economies, such as tourism and marine harvesting/farming. We extend research on referendumbased coastal water quality management in three important ways: (i) evaluating citizen preferences for allocating public funds to alternative coastal water quality strategies, including the elicitation of preferences from those who vote no on a referendum, (ii) providing insight into tradeoffs 
citizens make between allocating funds to preventative coastal water quality strategies (e.g., updating and improving septic systems) or to adaptive strategies (i.e,. monitoring water quality) using a shares-allocation model (i. e., fractional multinomial logit), and (iii) determining the influence of choice architecture (e.g., offering cues to voters about the effects of coastal water quality on either public health or the marine environment) on citizens' referendum choice. Our results suggest two key insights for policy: first, citizens who may vote no on a referendum behave differently than those who vote yes; in our findings, yes voters are more likely to allocate funds to preventative strategies relative to no voters (e.g., updating and improving septic systems relative to monitoring). Second, providing cues to voters also influences allocation behavior. Our findings indicate that when cued with public health as a coastal management issue, respondents allocate more funds to monitoring relative to preventative strategies. These results can assist decision makers in thinking strategically about the language used to communicate coastal water quality issues, particularly in budget referenda.

\section{Previous Research and Current Hypothesis}

\section{Contributing to Coastal Water Quality and Allocation of Funds}

Enhancing understanding of citizen willingness-to-pay for coastal water quality improvements strengthens the ability of federal, state, and local decisionmakers to make informed decisions about diverse policies and projects in the coastal zone. A growing literature on willingness-to-pay for coastal resource management emphasizes the importance of individual attitudinal and behavioral constructs (Langford et al. 2000, Kontogianni et al. 2003, Genius et al. 2005, Halkos and Matsiori 2012) in decision making. A robust literature exists on valuation of coastal water quality as a key natural resource (Olmstead 2010) and provider of ecosystem benefits (Kosenius and Markku 2015), spanning topics such as fishing (Massey, Newbold, and Gentner 2006), beach recreation (Bockstael, Hanemann, and Kling 1987), and public health risk (Langford et al. 2000, Machado and Mourato 2002, Fleisher and Kay 2006). These studies find that many socioeconomic factors affect citizen willingness-to-pay for improvements or protection of coastal zones. Demographic results indicate that older individuals are willing to pay less for coastal water quality programs; conversely, individuals with higher education and income and children in their homes are willing to contribute more (Kontogianni et al. 2003, Genius et al. 2005, Eggert and Olsson 2009, Halkos and Matsiori 2012). Studies have also attempted to capture the motivations behind willingness-to-pay for coastal water quality, including an individual's perceived importance of environmental protection (Kontogianni et al. 2003, Halkos and Matsiori 2012), risk 
perception (Langford et al. 2000, Hunter et al. 2012, Hynes, Tinchy, and Hanley 2014,), and coastal recreation habits (Kontogianni et al. 2003, Hynes, Tinchy, and Hanley 2014). We note a gap in the literature where there is limited information about citizen preferences for the allocation of funds designated for coastal zones, and factors affecting these allocation choices. Increasingly, decision makers and citizens alike are no longer satisfied with processes involving scientific information, which fail to allow society to participate (Gibbons 1999). Further, participation by the public contributes to both science generation (science for policy) but also in setting scientific agendas and priorities (policy for science) (McNie 2007).

Economists have long focused on the efficiency of management resource distribution across fields as varied as conservation policies (Wu 2004), farmland preservation (Deaton et al. 2003), land-use change (Bell, Boyle, and Rubin 2006), cap-and-trade emissions allowances (Shobe et al. 2010), and fisheries (Anderson 2010). This research has focused on various criteria for allocating resources including benefit-costs (i.e., highest benefit-cost ratios), targeting benefit maximization (larger environmental benefit for a given budget), historical allocation, shares modeling, and ecological production theory (Boyd and Krupnick 2013). Researchers may attempt to include the preferences of stakeholders or other representatives in these criteria, given that resource allocation decisions have substantial impact on citizens. Noblet et al. (2015) examine citizen preferences for investment tradeoffs in renewable energy and energy efficiency following a willingness-to-pay scenario for energy policy. Blomquist et al. (2004) use a seemingly unrelated regression analysis on their contingent budget choice data to explore citizen allocation of funds toward differing transportation policy alternatives. (McDaniels 1996) uses a structured value referendum (SVR) to collect information on citizen preferences for environmental policy alternatives, citing advantages such as decision consequentiality and salience. McDaniels (1996) emphasizes the development of relevant policy alternatives including the status quo, the inclusion of practical tradeoffs, and the incentive compatibility of the choices provided. Blomquist et al. (2004, p. 54) note that, "[a]n advantage of the relative values... is not only that the programs can be rank ordered by priority, but also that they can be compared with respect to relative importance. In other words, a change in a program may be ranked above a change in another program and be valued twice as much." In these studies, only allocation preferences from individuals willing to support/pay for a proposed policy change are included - a gap we seek to fill with the current work. Consistent with Halkos and Matsiori (2012), we invite participants to indicate their willingness-to-pay in a referendum-based contingent valuation scenario and then distribute the funds between various priorities of coastal water quality programs. We collect this specialized data to test our first hypothesis. 
Hypothesis 1: Citizen allocation of funds to adaptive versus preventative strategies for addressing coastal water quality will vary systematically by individual characteristics, including whether or not a participant voted in support (or opposition) of the proposed coastal water quality program.

\section{Context Dependency and Consequentiality}

The behavioral environmental economics literature indicates that choice architecture is an important tool for communicating complex environmental decisions (Van de Velde et al. 2010, Scannell and Gifford 2013). Noblet, Anderson, and Teisl (2015) find evidence of context dependent public policy preferences, providing motivation for the current work to investigate the role of message framing in citizens' coastal water quality choices. Similarly, work on motivational versus sacrificial language in messaging about climate change shows motivational frames increased perceived climate change competence, engagement, and behavioral intentions (Gifford and Comeau 2011). Pulling heavily from Tversky and Kahneman's (1981) prospect theory, Spence and Pidgeon (2010) find that preventative action and gain framing elicited positive feelings from individuals, and suggest that prevention behaviors are perceived to be low risk. Morton et al. (2011) go a step further and explore both positive (gain) and negative (loss) message framing in a climate change uncertainty context, noting that negative or loss framing under high uncertainty results in decreased intentions for taking climate-change-relevant action, whereas positive or gain framing results in consistent intentions for taking climate-change-relevant action across high and low uncertainty. Looking at citizen choices with regards to public policy and environmental management, we lay the groundwork for our second hypothesis by drawing a link between motivational/positive versus sacrificial/loss framing and proactive versus reactive environmental management strategies. Further, work across the disciplines of economics and psychology note that individuals are often swayed by consideration of others during decision making. Considering the choices that others may make is often a simplification strategy in decision making (Schwenk 1984), particularly if one considers the choices others in their relevant in-group may make (Yzerbyt and Demoulin 2010). Decision making may also be seen as an opportunity to pursue social justice (Jost and Kay 2010). The influence of others in environmental decision making may also depend on whether one has faith that others will perform the same pro-environmental behavior (Berger and Corbin 1992) or perceive that collective action will be effective (Ellen, Wiener, and Cobb-Walgren 1991, Cojuharenco, Cornelissen, and Karelaia 2016). Finally, research has shown that individuals may make very different choices when they are called upon to make decisions as a citizen than they may as a consumer (Nyborg 2000). Thus, when considering citizens' choices 
regarding public policy the potential for external influences is great, including recent studies finding that citizens' perspectives on the consequences of their policy choices may affect valuation efforts (Carson and Groves 2007, Carson, Groves, and List 2014). It seems that for truly robust contingent valuation methodology, consequentiality matters; this means that respondents must feel that their responses have consequence, and they must care about the outcome scenarios (Carson and Groves, 2007, Vossler and Evans 2009, Vossler and Watson 2013). Additionally, pro-environmental behaviors may differ across individuals who attribute responsibility for the environment to others, including government entities (Kalamas, Cleveland, and Laroche 2014). The literature on framing and the role of policy consequentiality informs our second hypothesis.

Hypothesis 2: Allocation choices will be affected by the context in which information is presented including (i) framing of the problem (impacted resource, i.e., shellfish or beaches; affected party, i.e., marine environment or public health), (ii) perception of the management action (i.e., adaptive or preventative measures), and (iii) perceived consequentiality of citizen input.

\section{Methods}

\section{Survey Design and Administration}

We designed a survey to capture citizen perceptions of current coastal water quality and preferences for future management measures. The design of the survey was informed by both state agency stakeholders and a mixed-mode pilot survey administered in the spring of 2015, where participants received a letter by postal mail with an invitation to participate and included a web address for the survey, to be typed into their web browser. The pilot survey (10 percent response rate) was sent to the target population of Maine and New Hampshire Coastal residents, where names/addresses of residents were purchased from InfoUSA, a database company. ${ }^{1}$ We requested a list of residents from coastal zone areas in each state, as defined by their respective Coastal Zone Programs, and provided InfoUSA a list of zip codes for these coastal towns. ${ }^{2}$ The pilot survey offered an excellent opportunity to test our survey questions on our population of interest (Fox et al. 2016) and we we adjusted the final mail survey as a result of this pilot.

\footnotetext{
1 More information on InfoUSA and the services they provide can be viewed at www.infousa. com.

2 Zip codes were selected from the Maine and New Hampshire Coastal Zone Programs NHCP2017, MCP2013.
} 
Two key outcomes from the pilot survey emerged linked to our two current hypotheses. First, qualitative results from the pilot indicated that individuals who voted no on the referendum sought an opportunity to express their allocation preferences; asking these respondents about their allocation choices may be fruitful (Hypothesis 1). ${ }^{3}$ Second, the pilot survey results yielded information that residents who ranked public health or environmental (marine) health as a top concern in coastal zone management were more willing to contribute to a hypothetical Coastal Water Quality Improvement Program (Fox et al. 2016). These results motivated our desire to vary the context information presented to survey participants and observe the impact on valuation and allocation decisions (Hypothesis 2).

We thus redesigned and redeployed our survey to a new sample. The current analysis is based on this redesigned survey, which was deployed by postal mail in August 2015 to coastal residents of Maine and New Hampshire, United States. Participants were recruited using names and addresses of residents purchased from InfoUSA using the same zip codes as our pilot study. The survey proceeded in a two-round modified tailored design method (Dillman, Smyth, and Christian 2014), where participants received an initial invitation followed by the survey instrument and one-dollar incentive. A subsequent round contained a copy of the survey and a reminder letter. We received 1,176 survey responses (survey response rate $=32.9$ percent), but not all respondents completed all questions. Our model sample is based on the subset of respondents that completed the referendum and allocation questions, and provide a complete set of relevant explanatory variables. This generated a model sample of 780 (model response rate $=22$ percent). We examine the representativeness of our modeling sample compared to our target population demographics (Table 1) and note that our sample is slightly more male, older, and wealthier than the target population. ${ }^{4}$

To test our first hypothesis, participants were provided with a policy scenario (Figure 1) introducing a new hypothetical Coastal Water Quality Program. Respondents were then asked a referendum-style contingent valuation question followed by an allocation-of-funds question. We did not provide respondents with any additional information beyond that which was presented in Figure 1 about either the proposed program or the potential allocation categories, as we wish to capture the variation across respondents in preferences for policy action. We acknowledge that the lack of additional information about the scenario may have contributed to the drop in participation from respondents in both the valuation question and the

\footnotetext{
3 We recognize that participants who responded 'no' to our contingent valuation question may have a nonzero willingness-to-pay or contribute to the proposed Coastal Water Quality policy but were perhaps faced with a fee above their willingness-to-pay.

4 Coastal towns included in our survey generally represented a wealthier demographic than the state averages.
} 
Table 1. Demographic Profile. Respondents used in analysis $(\mathrm{N}=780)$ and U.S. Census data for sample towns/ state.

\begin{tabular}{llll}
\hline Maine (N= 532) & Respondents & Census, Sampled Town & Census, Sampled States \\
\hline Gender (\% male) & 59.6 & 52.6 & 49 \\
Age (mean, years) & 57.3 & 48.1 & 43.2 \\
Income (median annual household, \$) & $\$ 79,388$ & $\$ 62,900^{*}$ & $\$ 48,804^{*}$ \\
Education attainment & $\begin{array}{l}98.3 \% \text { attained a high school } \\
\text { degree or higher }\end{array}$ & Not available & $\begin{array}{c}91.3 \% \text { attained a high school } \\
\text { degree or higher* }\end{array}$ \\
\hline New Hampshire (N $=\mathbf{2 4 8 )}$ & Respondents & Census, Sampled Town & Census, Sampled States \\
\hline Gender (\% male) & 57.3 & 51.6 & 49.4 \\
Age (mean; years) & 55.3 & 44.3 & 41.5 \\
Income (median annual household, \$) & $\$ 83,002$ & $\$ 68,970^{*}$ & $\$ 64,916^{*}$ \\
Education attainment & $100 \%$ attained a high school & Not available & $92.0 \%$ attained a high school \\
& degree or higher & & degree or higher* \\
\hline
\end{tabular}

*Source: 2010-2014 American Community Survey 5-year estimates for Maine and New Hampshire. Census information from towns represents a sub-sample of coastal zone towns. 


\section{Please read this information:}

A new program has been proposed to address coastal water quality. Please think about coastal water quality in terms of $<<$ FRAME $>>$.

The proposed Coastal Water Quality Program would be funded by all $<<$ STATE $>>$ households, who would be required to pay a fee through higher water/sewer/septic fees. The program would be created by majority vote.

If the Coastal Water Quality Program would cost your household an additional $\$<<$ FEE $>>$ per month, would you be willing to pay that amount and support the program? (CHECK ONE.)

Yes, I would be willing to pay the increase in fees to support the Coastal Water Quality Program.

No, I would not be willing to pay the increase in fees to support the Coastal Water Quality Program.

How much of the Coastal Water Quality Program budget would you like to see put towards each of the following actions? (Your values should sum to $100 \%$ ).

$\% \quad$ Improving water quality monitoring to detect pollution levels and sources

$\% \quad$ Educating and/or providing financial resources to municipal officials

$\%$ Better management of industrial development

$\%$ Better management of residential development

$\%$ Improving home and garden practices

$\% \quad$ Updating and maintaining septic systems

$\%$ Improving wastewater treatment, sewer and stormwater runoff infrastructure

Figure 1. Contingent Valuation and Allocation Questions. «STATE Maine or New Hampshire. «FEE , 5, 7, 10, 15 and 20. 
allocation question. The response categories in the allocation question were randomly varied across respondents to mitigate order effects; the categories presented to respondents were informed by state agency decision makers. Importantly for this study, even participants who indicated they were not willing to pay the fee faced in the contingent valuation scenario (i.e., voted no in the referendum question) were given the opportunity to indicate their allocation preferences across seven categories. Participation in the allocation question across these two groups was similar, 89 percent of those who voted yes went on to complete the allocation question; 76 percent of those who responded they were not willing to pay the fee associated with the Coastal Water Quality Program (voted no), completed the allocation question. While we did not receive 100 percent joint participation in the $\mathrm{CV}$ and allocation questions, and this is not surprising. We acknowledge that our allocation question may have been cognitively challenging, as our question asked respondents to allocate funds to seven different options, where the sum of the percentages should equal 100. Further, we also acknowledge that respondents differed in their pre-existing knowledge of coastal water quality issues, and that lack of knowledge about the aspects of coastal water quality degradation (ex: septic systems, development) or the entities responsible for enforcement (e.g., municipal officials) may have made the allocation question intimidating.

Based on our findings from the pilot survey, we created multiple versions of the survey (Table 2). First, we recognized that citizens in Maine and New Hampshire faced different institutional contexts, and thus respondents received a survey that used their state name. Second, to vary the context in which respondents were making decisions, half of our surveys focused on shellfish as a resource affected by coastal water quality, and the other half of our surveys focused on beaches. Thus, the cover graphic of these two versions differed, and in Section 3 of all surveys, participants responded to questions about either shellfish consumption or beach use. Third, throughout the survey, participants were asked to consider coastal water quality, including during the contingent valuation scenario and subsequent allocation decisions (Figure 1). One half of our sample was asked to consider coastal water quality in terms of "public health" and the other half in terms of "the marine environment". This frame appeared in Sections 2, 4, and 5. All respondents indicated preferences about coastal water quality program outcomes and answered a question about the policy consequentiality of their responses. Respondents answered a myriad of opinion questions including their trust in scientists, risk information, responsibility ascription, and demographic questions.

\section{Economic Theory}

The budget share-allocation problem faced by survey respondents can be represented as a simple utility maximization problem with exogenous budget constraint and bounded share-allocations. Suppose there exists a wellbehaved, twice-differentiable utility function for respondent $i$, for which they 
Table 2. Description of the Survey Versions

\begin{tabular}{lll}
\hline Survey Section & Focus of Section & Beach Version
\end{tabular}

«STATE» Maine or New Hampshire (e.g., In your opinion, how much of a negative impact do the following have on coastal water quality in Maine?)

«FRAME» public health or health of the marine environment (e.g., Please think about coastal water quality in terms of public health, including the safety of swimming in the water and shellfish harvesting from flats and waters)

$\ll$ FEE» Vary monthly cost of referendum. Takes on the values $\$ 2,5,7,10,15$ and 20 
are tasked to allocate budget shares across $M$ categories. The allocation problem can then be written as,

$$
\begin{aligned}
& \max _{\left\{s_{k}\right\}_{k=1}^{M}} U_{i}\left(s_{1}, \cdots, s_{M}\right) \quad \text { subject to } \sum_{k} s_{k}=1, \\
& 0 \leq s_{k} \leq 1 \text { for } k=1, \cdots, M
\end{aligned}
$$

Let $s_{i k}^{*}$ denote respondent $i$ 's optimal allocation to category $k$, which depends on the unobservable preferences of the individual. The actual budget-share allocation $s_{i k}$ observed in the survey may differ from the optimal allocation due to unobservable information or random events influencing the respondent's behavior $\epsilon_{i k}$.

$$
s_{i k}=s_{i k}^{*}+\epsilon_{i k}
$$

These random events are assumed to have a zero mean, implying $E\left[s_{i k}\right]=s_{i k}^{*}$. Our economic model is built upon estimating these conditional expectations, which may be a function of individual characteristics.

\section{Fractional Multinomial Logit Model}

The fractional multinomial logit (FMNL) model, a generalization of the fractional logit model developed by Papke and Wooldridge (1996), focuses on the conditional mean allocation of the budget-shares across categories. In this model, these conditional means are influenced by characteristics unique to respondents $X$ (e.g., socioeconomic characteristics, risk perceptions and risk preferences) and can be described by a predetermined function $G(\cdot)$. That is, the expected allocation to category $k$ by respondent $i$, given some observable information $X_{i}$, takes the general form,

$$
E\left[s_{k} \mid X_{i}\right]=G_{k}\left(X_{i}, \beta\right) \equiv G_{i k}(\beta) \text { for } i=1, \cdots, N ; k=1, \cdots, M
$$

where $\beta=\left(\beta_{1}, \cdots, \beta_{M}\right)$ denotes a stacked vector of model parameters. The FMNL model employs a multinomial logit (MNL) specification for $G(\cdot)$,

$$
G_{k}\left(X_{i}, \beta\right)=\left\{\begin{array}{lc}
\frac{\exp \left(\beta^{\prime}{ }_{k} X_{i}\right)}{1+\sum_{m=1}^{M-1} \exp \left(\beta_{m}^{\prime} X_{i}\right)} & \text { for } k=1, \cdots, M-1 \\
\frac{1}{1+\sum_{m=1}^{M-1} \exp \left(\beta_{m}^{\prime}{ }_{m}\right)} & \text { for } k=M
\end{array}\right.
$$

which fixes $\beta_{M}=0$. As such, all parameter estimates of this model are defined relative to this base case. 
The MNL specification (i.e., the FMNL model) is commonly used in the literature under a variety of settings: estimating expenditure shares (Koch 2010), time allocation of individuals across health care activities (Mullahy and Robert 2010), transportation time (Sivakumar and Bhat 2002), and modeling financial asset portfolio shares (Mullahy 2015). This specification is desirable because it is simple to implement and interpret, and maintains the constraints from the theoretic economic model. The expected budget-shares are constrained to lie within the unit interval $\left(0 \leq G_{i k} \leq 1 \forall i, k\right)$, and these shares sum to unity for all respondents in the sample. Other specifications for $G(\cdot)$ are possible but may be inappropriate in our context. For example, the Dirichlet distribution, an alternate choice to the MNL specification, cannot handle a single category receiving the entire allocation. Further, work by Murteira and Ramalho (2016) suggests that the quasi-maximum likelihood estimation of the FMNL model may outperform alternative specifications. A description of these alternative specifications and their underlying assumptions falls beyond the scope of this paper (see Mullahy (2015) for a detailed discussion).

Given the MNL specification, the log-likelihood function for the FMNL model takes the form,

$$
L L(\beta)=\sum_{i=1}^{N} \sum_{k=1}^{M} s_{i k} \log G_{i k}(\beta) .
$$

We use the statistical module FMLOGIT (Buis 2008) for STATA 14 to estimate the FMNL model.

\section{Evaluation of Fit}

Following (Sivakumar and Bhat 2002), we employ McFadden's adjusted $\mathrm{R}^{2}$ (adjusted likelihood ratio index) to evaluate model fit. McFadden's adjusted $\mathrm{R}^{2}$ is defined as,

$$
\text { adjusted } R^{2}=1-\frac{L L(\widehat{\beta})-K}{L L(0)}
$$

where $L L(\widehat{\beta})$ and $L L(0)$ are the log-likelihood function values evaluated at the parameter estimates and zero (intercept only model) respectively, and $K$ is the number of parameters estimated in the model.

\section{Data}

Dependent variables: The design of the allocation choice forced respondents to make tradeoffs between seven coastal water quality program components. Our budget allocation question did not include the status quo alternative; rather, the 
scenario developed implies that the budget is contingent upon voter support and funding from a monthly increase in citizen sewer/water/septic bills. By design, citizen assignment of budget-shares towards policy action alternatives requires the consideration of practical tradeoffs - an increase of 1-percent budget-share toward one policy alternative necessitates a proportionate decrease toward some combination of the other alternatives. Recognizing that preventative measures that seek to prevent coastal water quality impairment and adaptation strategies are needed in light of impairment will both be components of successful coastal zone management we include both in our response categories. We include improving water quality monitoring as an adaptation strategy, while the other six program options are best characterized as preventative. We are interested in determining how characteristics of the individual and architecture of the choice, affect allocation of funds to these broad categories, which motivates our use of the category Monitor as our reference category (base) during regression analysis.

Explanatory Variables: Consistent with Hypothesis 1, we include variables that capture multiple facets of an individual respondent (Table 3). We capture traditional socioeconomic variables of income, education, male and age. Given that our data set includes respondents from two states, we also control for differences between Maine participants and New Hampshire participants using a dummy variable, State. Research has also shown that place attachment may affect individuals' choices regarding the environment of their state (Walker and Ryan 2008, Lokocz, Ryan, and Sadler 2011). We proxy this attachment by including the number of years a respondent has lived in their state. Place attachment research notes strong support by local residents for preserving rural character in their areas. Consistent with the risk literature, awareness of an issue and perception of risk associated with the issue affect behavioral decisions (O'Conner, Bord, and Fischer 1999, Langford et al. 2000). We proxy awareness of coastal water quality impairment with two variables: (i) Closure indicates whether a participant has seen/heard of a shellfish area closure and (ii) Advisory indicates whether the individual has seen/heard of a beach advisory, indicating that water may be unsafe to enter due to bacterial levels. We include Beach sick and Shellfish sick to capture the perceived likelihood of illness occurring if a person consumes shellfish/ enters the water at a beach during an advisory. We expect that greater awareness of coastal water quality impairment and higher perceived risk will affect allocation of funds for preventative measures. Given that coastal water quality impairment is often not visible, citizens must rely on scientists to relate information on the state of the resource. Prior work has noted that citizens' trust of science may affect their choices regarding sustainability issues (Bromme and Goldman 2014). We create a composite variable across six questions (example: scientists provide reliable information, Chronbach's $\alpha=0.89)$ answered on a Likert scale $(1=$ strongly disagree, $7=$ strongly agree), where a higher score indicates a greater trust in scientists. We also 
Table 3. Descriptive Statistics of Dependent and Explanatory Variables. Dependent variables represent the percent of the Coastal Water Quality Project budget assigned to the specified category.

\begin{tabular}{|c|c|c|c|}
\hline Variable & Description & Mean & Std. Dev. \\
\hline \multicolumn{4}{|c|}{ Dependent Variables } \\
\hline Garden & Home and garden practices & 6.903 & 7.878 \\
\hline Septic & Updating and maintaining septic systems & 14.539 & 12.459 \\
\hline Runoff & Improving wastewater, sewer/runoff infrastructure & 26.140 & 17.274 \\
\hline Monitor & Improving water quality monitoring & 17.704 & 14.400 \\
\hline Educ & Education/financial resources to municipal official & 9.028 & 9.731 \\
\hline RedDev & Better management of residential development & 10.695 & 9.575 \\
\hline IndDev & Better management of industrial development & 14.992 & 12.125 \\
\hline \multicolumn{4}{|c|}{ Explanatory Variables } \\
\hline Survey type & Shellfish version $=1$; Beach version $=0$ & 0.500 & 0.500 \\
\hline Frame & Marine environment $=1$; Public health $=0$ & 0.490 & 0.500 \\
\hline Vote & If 'yes' on referendum $=1$; If 'no' on referendum $=0$ & 0.612 & 0.488 \\
\hline Fee & Fee amount, $\$ 2,5,7,10,15$ and 20 & 9.886 & 6.236 \\
\hline Advisory & Heard $/$ seen beach advisory $=1$; Otherwise $=0$ & 0.276 & 0.447 \\
\hline Closure & Heard/seen shellfish closure $=1$; Otherwise $=0$ & 0.408 & 0.492 \\
\hline Beach sick & Likelihood of illness from advisory $(0-100)$ & 22.728 & 29.164 \\
\hline Shellfish sick & Likelihood of illness from closure $(0-100)$ & 32.764 & 37.901 \\
\hline Trust science & Composite variable & 5.135 & 1.060 \\
\hline Safety & Importance of beach safety as a project outcome; 1 (not) -7 (very) & 4.709 & 1.504 \\
\hline Harvest & Importance of harvesting as a project outcome; 1 (not) - 7 (very) & 5.056 & 1.481 \\
\hline
\end{tabular}




\begin{tabular}{|c|c|c|c|}
\hline Healthy & Importance of healthy marine environment as a project outcome, 1 (not) - 7 (very) & 6.072 & 1.090 \\
\hline Experience & Importance of improved costal experience as a project outcome, 1 (not) - 7 (very) & 4.865 & 1.445 \\
\hline Votes Matter & Votes on proposal taken into account, 1 (definitely not) - 5 (definitely is) & 2.884 & 1.024 \\
\hline Income & Income (in tens of thousands) & 9.525 & 6.067 \\
\hline Education & Education (years) & 15.474 & 2.088 \\
\hline Male & Male $=1$, Female $=0$ & 0.588 & 0.492 \\
\hline Age & Age (years) & 56.809 & 14.588 \\
\hline Years in state & Years lived in state & 35.316 & 20.697 \\
\hline State & New Hampshire $=1$, Maine $=0$ & 0.318 & 0.466 \\
\hline
\end{tabular}


wish to capture information on the a priori benefits of coastal water quality perceived by respondents. Participants indicated the importance of four potential outcomes of a coastal water quality program on a Likert scale $(1=$ not at all important; $7=$ very important): Safety, Harvest, Healthy and Experience. Our allocation exercise was located after a standard referendumstyle contingent valuation scenario including a variable Fee. The variable Fee was presented as a per-month surcharge to support the hypothetical Coastal Water Quality Program. Fee could take a value of $\$ 2,5,7,10,15$ or 20 (Figure 2 shows responses to the referendum question at each fee level). Values were selected based on input from state agency stakeholders. We wish to examine whether participants who voted in support of (or opposition to) the coastal water quality program differed in their allocation choices and further understand any role that the variable fee may have played in allocation choice. Participants who faced larger fees may have allocated the funds differently than those who faced smaller fees, perhaps considering how impactful these larger/smaller funds would be on a coastal water quality program.

To test our Hypothesis 2 regarding context dependence, including coastal water quality problem framing and the impacts of policy consequentiality, we include the following variables. First, Survey type is a variable that captures whether Section 3 of the survey focused on beach use or shellfish consumption. Related, the variable Frame denotes whether a participant was asked to think about water quality (during both rating and the contingent valuation scenario) in terms of public health (coded as 1) or marine environment (coded as 0 ). We have no priors on these two variables; rather, we anticipate that framing may affect allocation but are uncertain of the nature of the relationships. We include responses to a policy consequentiality question, Votes matter, where respondents indicated on a Likert scale $(1=$ not taken into account, $7=$ definitely taken into account) how votes on the proposal would be taken into consideration by policy makers.

\section{Results and Discussion}

\section{Evaluating Hypothesis 1}

We first examine components of the individual respondent that influence decision making (Table 4). We find that males prefer to allocate funds towards the preventative actions relative to adaptive measures (the category labeled Monitor in Table 3). While Income and Education are generally highly correlated, we find that Income and Education have opposite effects on allocation choices. Interestingly, results indicate that individuals with higher income prefer to allocate more funds to monitoring than to three of the preventative categories (Educ, ResDev and IndDev). Future work examining the reasons for this result is warranted but potentially include that higher 


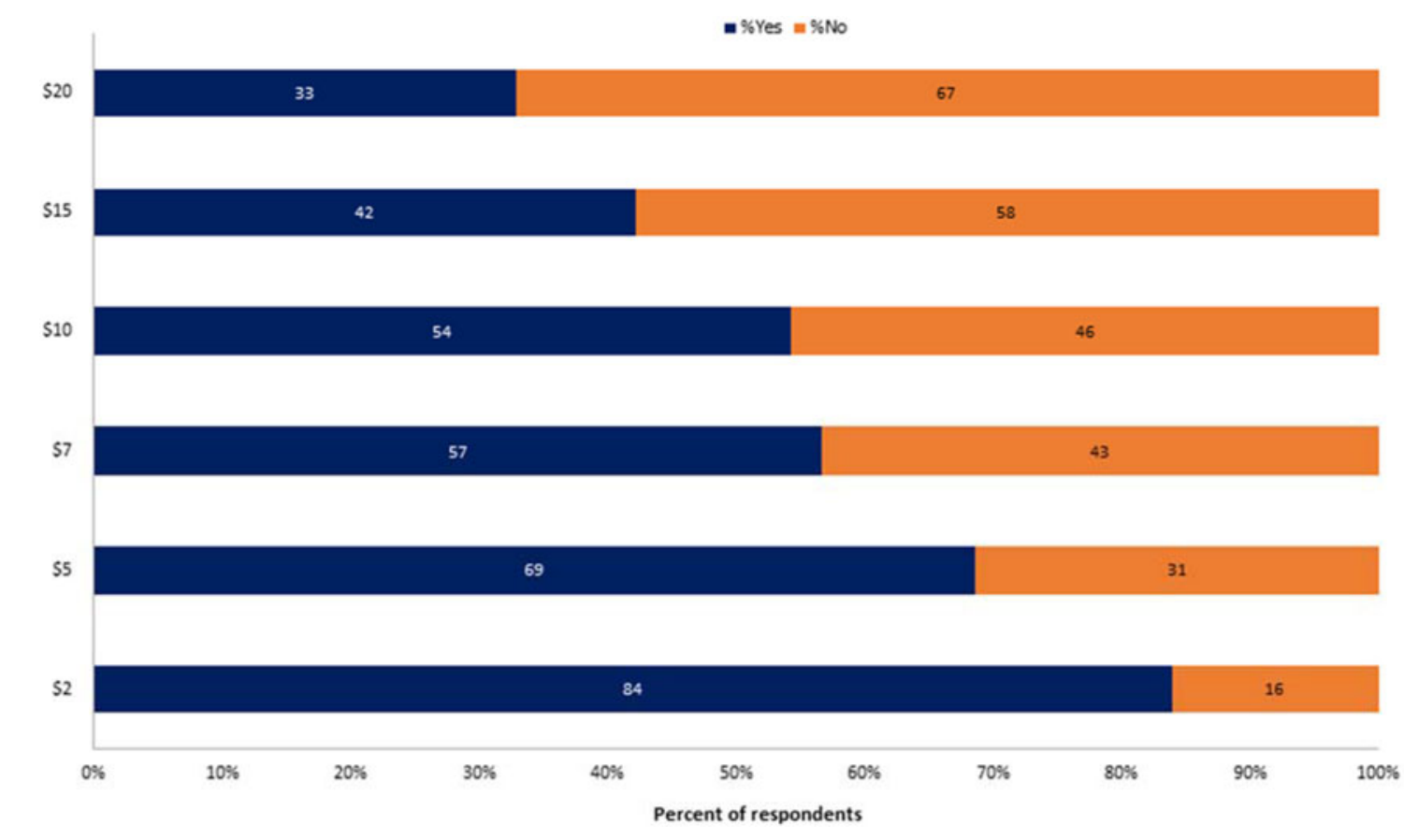

Figure 2. Participant Support (vote 'yes') for the Coastal Water Quality Program, by Fee Level. 
Table 4. Regression Table. Base category: Monitor - Improving water quality monitoring. Robust standard errors reported in parentheses.

\begin{tabular}{|c|c|c|c|c|c|c|}
\hline Variable & Garden & Septic & Runoff & Educ & ResDev & IndDev \\
\hline \multirow[t]{2}{*}{ Survey type (0/1) } & 0.138 & 0.373 & -0.012 & -0.211 & 0.148 & 0.050 \\
\hline & $(0.340)$ & $(0.286)$ & $(0.245)$ & $(0.280)$ & $(0.272)$ & $(0.267)$ \\
\hline \multirow[t]{2}{*}{ Frame $(0 / 1)$} & -0.143 & -0.115 & -0.087 & -0.078 & $-0.221^{* *}$ & $-0.207^{* *}$ \\
\hline & (0.109) & $(0.093)$ & $(0.081)$ & $(0.099)$ & $(0.098)$ & $(0.092)$ \\
\hline \multirow[t]{2}{*}{ Vote $(0 / 1)$} & $0.348^{* *}$ & $0.290^{* *}$ & 0.050 & 0.000 & 0.119 & 0.055 \\
\hline & $(0.137)$ & $(0.119)$ & $(0.098)$ & $(0.122)$ & $(0.116)$ & (0.109) \\
\hline \multirow[t]{2}{*}{ Fee } & 0.005 & 0.003 & -0.001 & 0.003 & 0.005 & $0.013^{*}$ \\
\hline & $(0.009)$ & $(0.008)$ & $(0.007)$ & $(0.008)$ & $(0.008)$ & $(0.008)$ \\
\hline \multirow[t]{2}{*}{ Advisory $(0 / 1)$} & 0.132 & 0.101 & 0.182 & 0.212 & 0.147 & -0.103 \\
\hline & $(0.168)$ & $(0.131)$ & $(0.117)$ & $(0.153)$ & $(0.140)$ & $(0.126)$ \\
\hline \multirow[t]{2}{*}{ Closure (0/1) } & -0.010 & -0.030 & 0.179 & 0.253 & 0.036 & 0.147 \\
\hline & $(0.204)$ & $(0.170)$ & $(0.137)$ & $(0.164)$ & $(0.169)$ & $(0.166)$ \\
\hline \multirow[t]{2}{*}{ Beach sick } & 0.000 & 0.000 & -0.000 & 0.001 & 0.001 & 0.003 \\
\hline & $(0.003)$ & $(0.003)$ & $(0.003)$ & $(0.003)$ & $(0.003)$ & $(0.002)$ \\
\hline \multirow[t]{2}{*}{ Shellfish sick } & -0.004 & -0.005 & -0.002 & -0.000 & -0.003 & -0.003 \\
\hline & $(0.003)$ & $(0.003)$ & $(0.002)$ & $(0.003)$ & $(0.002)$ & $(0.003)$ \\
\hline \multirow[t]{2}{*}{ Trust science } & 0.058 & -0.007 & -0.053 & -0.009 & 0.021 & -0.016 \\
\hline & $(0.065)$ & $(0.060)$ & $(0.056)$ & $(0.063)$ & $(0.064)$ & $(0.057)$ \\
\hline \multirow[t]{2}{*}{ Safety } & -0.045 & -0.043 & -0.001 & 0.044 & -0.043 & -0.001 \\
\hline & $(0.048)$ & $(0.039)$ & $(0.034)$ & $(0.040)$ & $(0.038)$ & $(0.037)$ \\
\hline \multirow[t]{2}{*}{ Harvest } & $-0.088^{* *}$ & -0.019 & -0.049 & -0.056 & $-0.087^{* *}$ & $-0.099 * * *$ \\
\hline & $(0.044)$ & $(0.035)$ & $(0.033)$ & $(0.038)$ & $(0.034)$ & $(0.034)$ \\
\hline
\end{tabular}




\begin{tabular}{|c|c|c|c|c|c|c|}
\hline Healthy & $\begin{array}{r}-0.044 \\
(0.075)\end{array}$ & $\begin{array}{r}-0.037 \\
(0.056)\end{array}$ & $\begin{array}{c}0.041 \\
(0.047)\end{array}$ & $\begin{array}{r}-0.066 \\
(0.051)\end{array}$ & $\begin{array}{r}-0.031 \\
(0.056)\end{array}$ & $\begin{array}{c}0.035 \\
(0.052)\end{array}$ \\
\hline Experience & $\begin{array}{r}-0.002 \\
(0.049)\end{array}$ & $\begin{array}{c}0.003 \\
(0.040)\end{array}$ & $\begin{array}{r}-0.063 * \\
(0.033)\end{array}$ & $\begin{array}{r}-0.072 * \\
(0.038)\end{array}$ & $\begin{array}{c}0.013 \\
(0.039)\end{array}$ & $\begin{array}{r}-0.004 \\
(0.036)\end{array}$ \\
\hline Votes matter & $\begin{array}{c}0.076 \\
(0.062)\end{array}$ & $\begin{array}{c}0.045 \\
(0.057)\end{array}$ & $\begin{array}{r}-0.029 \\
(0.048)\end{array}$ & $\begin{array}{c}0.118^{* *} \\
(0.057)\end{array}$ & $\begin{array}{r}-0.044 \\
(0.057)\end{array}$ & $\begin{array}{c}-0.005 \\
(0.055)\end{array}$ \\
\hline Income & $\begin{array}{c}-0.019 \\
(0.012)\end{array}$ & $\begin{array}{r}-0.007 \\
(0.010)\end{array}$ & $\begin{array}{c}-0.006 \\
(0.008)\end{array}$ & $\begin{array}{c}-0.024^{* *} \\
(0.010)\end{array}$ & $\begin{array}{c}-0.015^{*} \\
(0.009)\end{array}$ & $\begin{array}{r}-0.014^{*} \\
(0.009)\end{array}$ \\
\hline Education & $\begin{array}{c}0.031 \\
(0.025)\end{array}$ & $\begin{array}{r}-0.007 \\
(0.024)\end{array}$ & $\begin{array}{c}0.046^{* *} \\
(0.020)\end{array}$ & $\begin{array}{c}0.040 \\
(0.031)\end{array}$ & $\begin{array}{c}0.037 \\
(0.024)\end{array}$ & $\begin{array}{c}0.034 \\
(0.024)\end{array}$ \\
\hline Male & $\begin{array}{c}0.236^{* *} \\
(0.106)\end{array}$ & $\begin{array}{r}0.170^{*} \\
(0.092)\end{array}$ & $\begin{array}{l}0.249 * * * \\
(0.085)\end{array}$ & $\begin{array}{l}0.341^{* * *} \\
(0.108)\end{array}$ & $\begin{array}{l}0.225^{* *} \\
(0.100)\end{array}$ & $\begin{array}{c}0.179 * \\
(0.096)\end{array}$ \\
\hline Age & $\begin{array}{c}-0.001 \\
(0.004)\end{array}$ & $\begin{array}{c}0.002 \\
(0.003)\end{array}$ & $\begin{array}{c}0.002 \\
(0.003)\end{array}$ & $\begin{array}{r}-0.000 \\
(0.004)\end{array}$ & $\begin{array}{c}0.004 \\
(0.003)\end{array}$ & $\begin{array}{c}0.002 \\
(0.003)\end{array}$ \\
\hline Years in state & $\begin{array}{c}0.003 \\
(0.003)\end{array}$ & $\begin{array}{c}0.001 \\
(0.003)\end{array}$ & $\begin{array}{c}0.000 \\
(0.002)\end{array}$ & $\begin{array}{r}-0.003 \\
(0.003)\end{array}$ & $\begin{array}{c}0.001 \\
(0.003)\end{array}$ & $\begin{array}{c}0.001 \\
(0.003)\end{array}$ \\
\hline State & $\begin{array}{c}-0.017 \\
(0.115)\end{array}$ & $\begin{array}{r}-0.168 \\
(0.105)\end{array}$ & $\begin{array}{r}-0.067 \\
(0.087)\end{array}$ & $\begin{array}{r}-0.105 \\
(0.108)\end{array}$ & $\begin{array}{r}-0.189 * \\
(0.101)\end{array}$ & $\begin{array}{c}-0.113 \\
(0.100)\end{array}$ \\
\hline Constant & $\begin{array}{c}-1.204 \\
(0.776)\end{array}$ & $\begin{array}{c}0.024 \\
(0.553)\end{array}$ & $\begin{array}{c}0.153 \\
(0.526)\end{array}$ & $\begin{array}{r}-0.652 \\
(0.593)\end{array}$ & $\begin{array}{c}-0.503 \\
(0.526)\end{array}$ & $\begin{array}{c}-0.470 \\
(0.524)\end{array}$ \\
\hline $\begin{array}{l}\text { Number of observations } \\
\text { Adjusted } \mathrm{R}^{2} \\
\text { Wald }\left(\chi^{2}\right)\end{array}$ & $\begin{array}{r}780 \\
0.127 \\
207.173\end{array}$ & & & & & \\
\hline
\end{tabular}

Significance levels: *: $10 \%{ }^{* *}: 5 \%$ **: $1 \%$ 
income households may have more opportunities to recreate in coastal waters yielding the desire for monitoring. Increased opportunities may be afforded by owning homes with direct coastal access, boats, or other water-sporting devices often associated with higher-income households. In contrast, respondents with higher educational attainment prefer to allocate funds to the preventative category of Runoff relative to the the adaptive category Monitor; we consider that this variable may reflect information or knowledge differences in our respondents. Our state agency stakeholders indicate that aging wastewater treatment, sewer, and stormwater runoff infrastructure (Runoff) is a key contributor to coastal water quality degradation in our study area. Thus, it may be that individuals with higher levels of education are aware of the contribution of this issue, which explains the preference for allocation of funds towards these action categories.

Importantly, we find that the allocation preferences for individuals who were willing to support the proposed coastal water quality program differ from those who oppose, given the fee and scenario presented. Individuals supporting the proposed program allocated more funds to two preventative components (Garden and Septic) over the adaptive category Monitor. Importantly, these components target individual responsibility for protection of coastal water quality.

Supporters of the referendum may recognize that direct and upstream resource users, including themselves, are part of the problem and therefore responsible for solutions. Allocating funds to preventative components such as Garden and Septic may indicate this recognition of personal responsibility. Individuals who faced a higher fee chose to allocate more funds to addressing industrial development relative to monitoring. This suggests citizens consider the potential efficacy of their contributions, and large-scale challenges such as industrial development may require large-scale funding to address. Relative to Maine respondents, New Hampshire respondents preferred to allocate fewer funds to residential development relative to monitoring. This result may stem from New Hampshire's reliance on visitors to the wellknown sand beaches. Continuing to monitor and provide information to beach-goers on the high water quality along these beaches may be of particular importance to New Hampshire respondents. ${ }^{5}$

\section{Evaluating Hypothesis 2}

We examine the role of context dependency on allocation choices. We find that participants who were asked to consider their decisions under the public health frame (i.e., Frame $=0$ ) chose to allocate more funds to residential and industrial development management than monitoring. These actions are consistent with

\footnotetext{
5 New Hampshire was ranked second in the nation for coastal water quality (based on testing of water at beaches) in the 2014 Natural Resources Defense Council 'Testing the Waters' report (Dorfman and Haren 2014).
} 
taking preventative measures to protect public health rather than adaptive measures after impairment may already pose a public health risk.

Our scenario also provided an opportunity for respondents to indicate whether they perceived that their votes would have policy implications. We find that individuals who believed that their decisions mattered chose to allocate more funds to 'educating and/or providing financial resources to municipal officials.' While many choices regarding water quality are made at the state or federal level, local government is often involved with enforcement or notification in our study areas. For example, the Maine Healthy Beaches (MHB) program is charged with monitoring coastal water quality and posting advisories under conditions of impairment. While this program is funded by the U.S. Environmental Protection Agency, MHB is a collaborative state program that works closely with municipal officials to make decisions about beach advisories at the local level. Thus, the relationship we find between perceived consequentiality and allocation to municipal sources may indicate that our participants believe their input is most valued by local government.

A follow-up component to our valuation and allocation scenario allowed respondents to indicate what outcomes of a proposed coastal water quality program were important to them; our results shed light on the importance of understanding citizen priorities for program outcomes. Individuals who ranked shellfish harvesting (Harvest) as a priority outcome were more likely to allocate funds towards monitoring. These individuals may have preferences for locally produced shellfish and consider monitoring an opportunity to increase their awareness of the problem and undertake avoidance behaviors as needed. Our pilot survey results indicated that less attention is paid to beach monitoring information than to shellfish safety information (Fox et al. 2016) which may help explain the emphasis on monitoring by those who prioritized harvesting. We remain curious about if the emphasis on shellfish harvesting as a priority outcome of the project was due to personal preferences, or perceptions of public safety risks. These results may continue to highlight that people react differently when asked to consider the welfare of others in the public policy realm in contrast to considering only their own personal welfare, consistent with previous findings by the authors of context dependent public policy preferences (Noblet, Anderson, and Teisl 2015).

\section{Limitations of the Study}

The study area of this work limits the generalizability of our data. Maine and New Hampshire are resource-dependent states and are typically associated with high coastal water quality (Dorfman and Haren 2014); findings may differ greatly in areas with greater water quality impairment or lower resource dependence. These coastal areas are heavily visited by tourists, and our study captures only the preferences of people who own property in these coastal towns; 3 percent of our sample indicated the address where they received the survey was a seasonal residence. We therefore are not 
accurately capturing the referendum votes and allocation preferences of all Maine and New Hampshire coastal users. Importantly, recent work suggests that residents and visitors have different contribution preferences with regards to natural resources (Aoun 2015). We also recognize the cognitive limitations of our respondents. Our dependent variable design requires participants to allocate funds such that they sum to 100. Responses between 90 and 110 were scaled to 100 for our regression analysis; respondents outside these bounds were removed from the analysis. Robustness checks suggest that scaling these observations had no impact on the model results; results from these tests are available upon request. Further, our data reflect stated preferences. We recognize the implications for our conclusions given this data collection method, including the knowledge that participants have limited incentives to reveal truthful preferences (Grösche and Schröder 2011). However, we attempt to address this particular limitation with the inclusion of a policy consequentiality question as a way to gauge criterion validity (Vossler and Evans 2009). We note that our consequentiality question was located after the allocation decision, and the request for information about what outcomes of a program are important. We are uncertain if this placement affected how participants responded to this question, which motivates future work examining the impact of consequentiality question placement. Additionally, we note that question ordering may have affected our respondents' referendum vote and/or allocation choices. Our referendum-style contingent valuation question was located prior to the allocation question, and therefore some respondents may have voted prior to viewing the components of the program to which they could allocate funding (albeit because this was a mail survey, respondents could go back and change their mind). The referendum and allocation questions were located on facing pages of a survey booklet, and we are uncertain if some respondents glanced ahead to review the allocation options. Finally, we recognize that our respondents' decisions in both the contingent valuation and allocation questions may have been influenced by their perceptions of what other respondents decided. Our survey instrument notes that the the Coastal Water Quality Program would be "created by majority vote", but we do not capture our respondents' perception of other people's choices (i.e., whether the majority would indeed vote to create the program). Further, we would expect that an individual's expressed allocation of budget-shares may depend on expectation of other respondents choices, consistent with the faith-in-others and perceived consumer effectiveness literature (Ellen, Wiener, and Cobb-Walgren 1991, Berger and Corbin 1992) and the potential need to represent other citizens who were not asked to participate (Nyborg 2000). Our current data do not capture metrics for analyzing these effects but offer opportunities for potentially fruitful future studies. 


\section{Conclusions and policy implications}

Designing effective natural resource management programs that meet with public acceptance is increasingly important and challenging. Consistent with Burkhart and Chan (2017) we hypothesize that referendum-style choices are impacted by citizens' experiences and preferences for program components/outcomes as well as the contextual elements of the program proposal. Improved understanding of how households perceive outcomes associated with policies, even those who may not have supported the programs initially, improves the efficacy of future policy. Our study provides two key insights for policy design and implementation. First, public acceptance of policy initiatives is logically best measured by responses from the public. Our study suggests, consistent with prior work in an energy setting (Noblet et al. 2015), that citizens hold preferences for allocation of funding for natural resource management. Further, work across the disciplines has demonstrated that individuals are not solely concerned with the outcomes associated with a decision, but also the process by which it was made (Earley et al. 1990, Gregory, Lichstenstein, and Slovic 1993, Daly and Geyer 1994). Guo and Neshkova (2013) find that the incorporation of citizen preferences for budget allocation matters most when it bookends the budget process, i.e., information sharing at the start of the process and program assessment at the end. Incorporating citizen input at these stages allows decision makers to tailor project priorities to citizens' needs and create effective policies. Our present study provides this key information on citizen preferences for program elements at an early stage to our state agency partners before any budget process is underway. Our results indicate that differences exist between the preferences of citizens who support (or oppose) a referendum; at this time we are aware of no other studies modeling budget allocation responses from survey participants who voted against a hypothetical program. This is important because in practice, those who vote against a particular environmental policy in a referendum setting may end up having to pay to support that policy, should the referendum pass. Our experimental modification, which allows us to analyze the allocation preferences expressed by both the supporters and opponents of a water quality program, has greater research implications for illustrating how households view willingness to pay, versus how funds are allocated in practice.

Second, consistent with previous work (Noblet, Anderson, and Teisl 2015, Tinch, Colombo, and Hanley 2015) our study demonstrates contextdependent public policy preferences. Given that individuals differed in their allocation choice by both how the questions were framed and perceived policy consequentiality, this work has important implications for contingent valuation methodology. These implications include continued care and further research into contingent valuation design, and the context in which policy scenarios are presented to citizens. We see future research opportunities for investigating citizen budget allocation substitutions across categories and natural resource domains. 


\section{References}

Anderson, C.M. 2010. "An Experimental Analysis of a Points-Based System for Managing Multispecies Fisheries." Agricultural and Resource Economics Review 39(2): 227-244.

Aoun, D. 2015. "Who Pays More to Preserve a Natural Reserve, Visitors or Locals? A Confidence Analysis of a Contingent Valuation Application." Environmental Economics and Policy Studies 17(4): 471-486.

Bell, K.P., K.J. Boyle and J. Rubin (Eds.). 2006. Economics of Rural Land-Use Change. Ashgate Studies in Environmental and Natural Resource Economics.

Bennett, N.J. 2016. "Using Perceptions as Evidence to Improve Conservation and Environmental Management." Conservation Biology: The Journal of the Society for Conservation Biology 30(3): 582-592.

Berger, I.E., and R.M. Corbin. 1992. "Perceived Consumer Effectiveness and Faith in Others as Moderators of Environmentally Responsible Behaviors." Journal of Public Policy and Marketing 11(2): 79-89.

Blomquist, G.C., M.A. Newsome, and D.B. Stone. 2004. "Public Preferences for Program Tradeoffs: Community Budget Priorities." Public Budgeting \& Finance 24(1): 50-71.

Bockstael, N., W. Hanemann, and C. Kling. 1987. "Estimating the Value of Water Quality Improvements in a Recreation Demand Framework." Water Resources Research 23: 951-960.

Boyd, J., and A. Krupnick. 2013. "Using Ecological Production Theory to Define and Select Environmental Commodities for Nonmarket Valuation." Agricultural and Resource Economics Review 42(1): 1-32.

Bromme, R., and S.R. Goldman, 2014. "The Public's Bounded Understanding of Science." Educational Psychologist 49 (February 2015): 59-69.

Buis, M.L. 2008. FMLOGIT: Stata Module Fitting a Fractional Multinomial Logit Model by Quasi Maximum Likelihood. Statistical Software Components, Boston College Department of Economics. https://ideas.repec.org/c/boc/bocode/s456976.html

Burkhart, J., and N. Chan. 2017. "The Dollars and Sense of Ballot Propositions: Estimating Willingness to Pay for Public Goods using Aggregate Voting Data." Journal of the Association of Environmental and Resource Economists 4(2): 479-503.

Carson, R.T., and T. Groves, May 2007. "Incentive and Informational Properties of Preference Questions." Environmental and Resource Economics 37(1): 181-210.

Carson, R.T., T. Groves, and J. List. 2014. "Consequentiality: A Theoretical and Experimental Exploration of a Single Binary Choice." Journal of the Association of Environmental and Resource Economists 1(1): 171-207.

Carter, R.W.G. 2002. Coastal Environments: An Introduction to the Physical, Ecological, and Cultural Systems of Coastlines. Academic Press.

Clark, W.C., and N.M. Dickson. 2003. "Sustainability Science: The Emerging Research program." Proceedings of the National Academy of Sciences of the United States of America 100(14): 8059-8061.

Cojuharenco, I., G. Cornelissen, and N. Karelaia. 2016. "Yes, I Can: Feeling Connected to Others Increases Perceived Effectiveness and Socially Responsible Behavior." Journal of Environmental Psychology 48: 75-86.

Daly, J., and P. Geyer. 1994. "The Role of Fairness in Implementing Large-Scale Change: Employee Evaluations of Process and Outcome in Seven Facility Relocations." Journal of Organizational Behavior 15(7): 623-638.

Deaton, B., P. Norris, and J. Hoehn. 2003. "Setting the Standard for Farmland Preservation: Do Preservation Criteria Motivate Citizen Support for Farmland Preservation?" Agricultural and Resource Economics Review 32(2): 272-281.

Dietz, T., and P.C. Stern, National Research Council (U.S.). Panel on Public Participation in Environmental Assessment and Decision Making. National Research Council (U.S.). 
Committee on the Human Dimensions of Global Change. 2008. Public Participation in Environmental Assessment and Decision Making. National Academies Press.

Dillman, D.A., J.D. Smyth, and L.M. Christian. 2014. Internet, Phone, Mail, and Mixed-Mode Surveys: The Tailored Design Method, 4th Ed. John Wiley \& Sons, Inc.

Dorfman, M., and A. Haren. 2014. Testing the Waters: A Guide to Water Quality at Vacation Beaches. Tech. Rep., Natural Resource Defense Council. https://www.nrdc.org/sites/ default/files/ttw2014.pdf

Earley, P.C., G.B. Northcraft, C. Lee, and T.R. Lituchy. 1990. "Impact of Process and Outcome Feedback on the Relation of Goal Setting to Task Performance." Academy of Management Journal 33(1): 87-105.

Eggert, H., and B. Olsson. 2009. "Valuing Multi-Attribute Marine Water Quality." Marine Policy 33(2): 201-206.

Ellen, P.S., J.L. Wiener, and C. Cobb-Walgren. 1991. "The Role of Perceived Consumer Effectiveness in Motivating Environmentally Conscious Behaviors." Journal of Public Policy and Marketing 19(2): 102-117.

Fleisher, J.M., and D. Kay. 2006. "Risk Perception Bias, Self-Reporting of Illness, and the Validity of Reported Results in an Epidemiologic Study of Recreational Water Associated Illnesses." Marine Pollution Bulletin 52(3): 264-268.

Fleming, L., K. Broad, A. Clement, E. Dewailly, S. Elmir, A. Knap, S. Pomponi, S. Smith, H. Solo Gabriele, and P. Walsh, 2006. "Oceans and Human Health: Emerging Public Health Risks in the Marine Environment." Marine Pollution Bulletin 53(10): 545-560.

Fox, E., C.L. Noblet, K.P. Bell, A. Kaminski, M. Snell, and A. Eslin. 2016. Maine and New Hampshire coastal resident survey (pilot). School of Economics Staff Paper \#623, University of Maine.

Genius, M., M. Manioudaki, E. Mokas, E. Pantagakis, D. Tampakakis, and K. Tsagarakis. 2005. "Estimation of Willingness to Pay for Wastewater Treatment." Water Science and Technology: Water Supply 5(6): 105-113.

Gibbons, M., 1999. “Science's New Social Contract with Society.” Nature 402 (SUPP): C81-C84.

Gifford, R., and L. Comeau. 2011. "Message Framing Influences Perceived Climate Change Competence, Engagement, and Behavioral intentions." Global Environmental Change 21(4): 1301-1307.

Gregory, R., S. Lichtenstein, and P. Slovic. 1993. "Valuing Environmental Resources - a Constructive Approach." Journal of Risk and Uncertainty 7(2): 177-197.

Grösche, P., and C. Schröder. 2011. "Eliciting Public Support for Greening the Electricity Mix Using Random Parameter Techniques.” Energy Economics 33(2): 363-370.

Guo, H., and M.I. Neshkova. 2013. "Citizen Input in the Budget Process: When Does it Matter Most?" The American Review of Public Administration 43(3): 331-346.

Halkos, G., and S. Matsiori. 2012. “Determinants of Willingness to Pay for Coastal Zone Quality Improvement." The Journal of Socio-Economics 41(4): 391-399.

Hunter, P., N. Hanley, M. Czajkowski, K. Mearns, A. Tyler, L. Carvalho, and G. Codd. 2012. "The Effect of Risk Perception on Public Preferences and Willingness to Pay for Reductions in the Health Risks posed by Toxic Cyanobacterial Blooms." The Science of the Total Environment 1(426): 32-44.

Hynes, S., D. Tinch, and N. Hanley. 2014. "Valuing Improvements to Coastal Waters using Choice Experiments: An Application to Revisions of the EU Bathing Waters Directive." Marine Policy 40(1): 137-144.

Jost, J.T., and A.C. Kay. 2010. "Social justice: History, Theory, and Research." Handbook of Social Psychology.

Kalamas, M., M. Cleveland, and M. Laroche. 2014. "Pro-Environmental Behaviors for Thee but Not for Me: Green Giants, Green Gods, and External Environmental Locus of Control." Journal of Business Research 67(2): 12-22.

Kates, R.W. 2011. "What Kind of a Science is Sustainability Science?" Proceedings of the National Academy of Sciences of the United States of America 108(49): 19449-19450. 
Koch, S.F., October 2010. "Fractional Multinomial Response Models with an Application to Expenditure Shares." Presented at the 20th Conference of the Development Policy Research Unit and Trade \& Industry Policy Strategies, Johannesburg, South Africa.

Kontogianni, A., I. Langford, A. Papandreou, and M. Skourtos. 2003. "Social Preferences for Improving Water Quality: An Economic Analysis of Benefits from Wastewater Treatment." Water Resources Management 17(5): 317-336.

Kosenius, A.K., and O. Markku. 2015. "Ecosystem Benefits from Coastal Habitats: A ThreeCountry Choice Experiment." Marine Policy 58: 15-27.

Langford, I.H., S. Georgiou, I.J. Bateman, R.J. Day, and R.K. Turner. 2000. "Public Perceptions of Health Risks from Polluted Coastal Bathing Waters: A Mixed Methodological Analysis using Cultural Theory." Risk Analysis 20(5): 691-704.

Lokocz, E., R.L. Ryan, and A.J. Sadler. 2011. "Motivations for Land Protection and Stewardship: Exploring Place Attachment and Rural Landscape character in Massachusetts." Landscape and Urban Planning 99(2): 65-76.

Machado, F.S., and S. Mourato. 2002. "Evaluating the Multiple Benefits of Marine Water Quality Improvements: How Important are Health Risk Reductions?" Journal of Environmental Management 65(3): 239-250.

Maine Coastal Program, 2013. Coastal zone map. http://www.maine.gov/dacf/mcp/about/ coastalzonemap.htm

Massey, D.M., S.C. Newbold, and B. Gentner. 2006. "Valuing Water Quality Changes using a Bioeconomic Model of a Coastal Recreational Fishery." Journal of Environmental Economics and Management 52(1): 482-500.

McDaniels, T.L. 1996. "The structured value referendum: Eliciting References for Environmental Policy." Journal of Policy Analysis and Management 15(2): 227-251.

McNie, E.C. 2007. "Reconciling the Supply of Scientific Information with User Demands: An Analysis of the Problem and Review of the Literature." Environmental Science \& Policy 10(1): 17-38.

Morton, T., A. Rabinovich, D. Marshall, and P. Bretschneider. 2011. “The Future that May (or May Not) Come: How Framing Changes Responses to Uncertainty in Climate Change Communications." Global Environmental Change 21(1): 103-109.

Mullahy, J. 2015. "Multivariate Fractional Regression Estimation of Econometric Share Models." Journal of Econometric Methods 4(1): 71-100.

Mullahy, J., and S.A. Robert. 2010. "No Time to Lose: Time Constraints and Physical Activity in the Production of Health." Review of Economics of the Household 8(4): 409-432.

Murteira, J.M.R., and J.J.S. Ramalho. 2016. "Regression Analysis of Multivariate Fractional Data." Econometric Reviews 35(4): 515-552.

National Oceanic and Atmospheric Administration. 2013. National coastal population report: Population trends from 1970 to 2020. NOAA's State of the Coast. http://oceanservice. noaa.gov/facts/coastal-population-report.pdf

New Hampshire Coastal Program, 2017. Coastal zone map. http://www.des.nh.gov/ organization/divisions/water/wmb/coastal/documents/nhcoastalzonemap.pdf

Noblet, C.L., M. Anderson, and M.F. Teisl. 2015. “Thinking Past, Thinking Future: An Empirical Test of the Effects of Retrospective Assessment on Future Preferences." Ecological Economics 114: 180-187.

Noblet, C.L., M.F. Teisl, K.S. Evans, M. Anderson, S.K. McCoy, and E. Cervone. 2015. "Public Preferences for Investments in Renewable Energy Production and Energy Efficiency." Energy Policy 87: 177-186.

Nyborg, K. 2000. "Homo economicus and Homo politicus: Interpretation and Aggregation of Environmental Values." Journal of Economic Behavior and Organization 42(3): 305-322.

O’Conner, R.E., R.J. Bord, and A. Fischer. 1999. "Risk Perceptions, General Environmental Beliefs and Willingness to Address Climate Change." Risk Analysis 19(3): 461-471.

Olmstead, S.M. 2010. "The Economics of Water Quality." Review of Environmental Economics and Policy 4(1): 44-62. 
Papke, L.E., and J.M. Wooldridge. 1996. "Econometric Methods for Fractional Response Variables with an Application to 401(K) Plan Participation Rates." Journal of Applied Econometrics 11(6): 619-632.

Robbins, M., M. Simonsen, and B. Feldman. 2008. "Citizens and Resource Allocation: Improving Decision Making with Interactive Web-based Citizen Participation." Public Administration Review 68(3): 564-575.

Scannell, L., and R. Gifford. 2013. "Personally Relevant Climate Change: The Role of Place Attachment and Local versus Global Message Framing in Engagement." Environment and Behavior 45(1): 60-85.

Schwenk, C.R. 1984. "Cognitive Simplification Processes in Strategic Decision Making." Strategic Management Journal 5(2): 111-128.

Shobe, W., K. Palmer, E. Myers, C. Holt, J. Goeree, D. Burtraw, A. Barr, A. Bostian, I. Clark, K. Fox, C. Mallow, L. Osco, and S. St Hilaire. 2010. "An Experimental Analysis of Auctioning Emission Allowances under a Loose Cap." Agricultural and Resource Economics Review 39(2): 162-175.

Sivakumar, A., and C. Bhat. 2002. "Fractional Split-Distribution Model for Statewide Commodity Analysis." Transportation Research Record 1790: 80-88.

Spence, A., and N. Pidgeon. 2010. "Framing and Communicating Climate Change: The Effects of Distance and Outcome Frame Manipulations." Global Environmental Change 20(4): 656-667.

Tinch, D., S. Colombo, and N. Hanley. 2015. "The Impacts of Elicitation Context on Stated Preferences for Agricultural Landscapes." Journal of Agricultural Economics 66(1): 87107.

Tversky, A., and D. Kahneman. 1981. "The Framing of Decisions and the Psychology of Choice." Science 211: 453-458.

Van de Velde, L., W. Verbeke, M. Popp, and G. Van Huylenbroeck. 2010. "The Importance of Message framing for Providing Information about Sustainability and Environmental Aspects of Energy." Energy Policy 38(10): 5541-5549.

Vossler, C.A., and M.F. Evans. 2009. "Bridging the Gap between the Field and the Lab: Environmental Goods, Policy Maker Input, and Consequentiality." Journal of Environmental Economics and Management 58(3): 338-345.

Vossler, C.A., and S.B. Watson, 2013. "Understanding the Consequences of Consequentiality: Testing the Validity of Stated Preferences in the Field." Journal of Economic Behavior and Organization 86(C): 137-147.

Walker, A.J., and R.L. Ryan. 2008. "Place Attachment and Landscape Preservation in Rural New England: A Maine Case Study." Landscape and Urban Planning 86(2): 141-152.

$\mathrm{Wu}, \mathrm{J}$. 2004. "Using Science to Improve the Economic Efficiency of Conservation Policies." Agricultural and Resource Economics Review 33(1): 18-23.

Yzerbyt, V., and S. Demoulin. 2010. Intergroup Relations: Handbook of Social Psychology. John Wiley and Sons, Inc. 